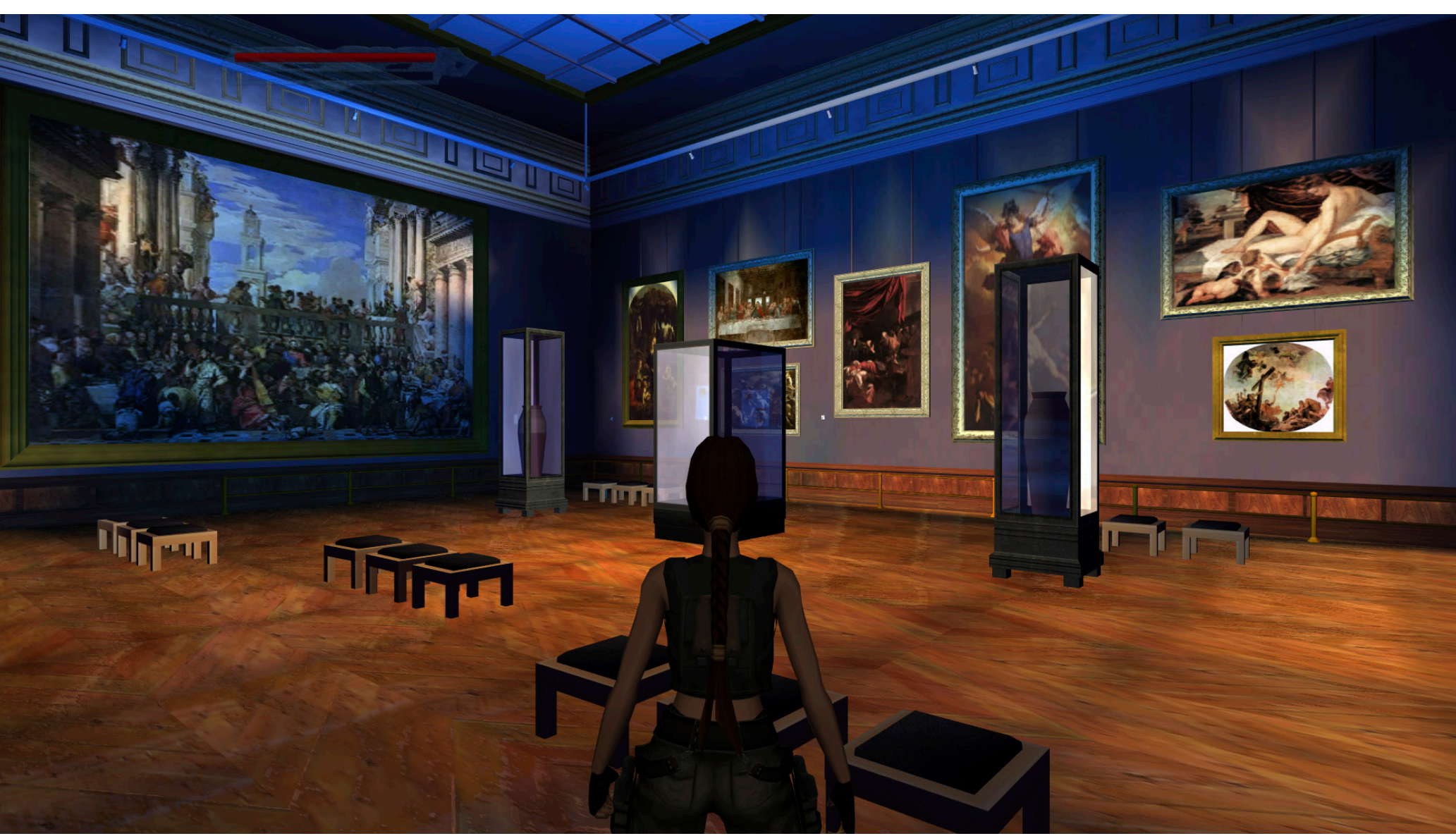

Fig.1. Captura de pantalla del interior del Museo del Louvre (Tomb Raider: El ángel de la oscuridad. Captura del autor. Derechos de Core Desing y Eidos Interactive). 


\title{
¡Roba, colecciona, mira y disfruta! Museos en videojuegos
}

Loot, Collect, Watch, and Enjoy! Museums in Videogames

\author{
Rafael Molina Martín \\ Universidad Pablo de Olavide, Sevilla, Espańa \\ molina.martin.rafael.hda@gmail.com \\ https://orcid.org/0000-0001-5728-0734
}

\section{Resumen}

Lugar de misterios o poso de la memoria de un colectivo, el museo se ha convertido en el escenario perfecto para el argumento de numerosos videojuegos. Gracias a ello, usuarios de todas las edades recorren estos escenarios virtuales con más frecuencia de lo que lo hacen en la vida real, abriendo sus puertas a nuevos públicos ¿Qué imagen se da en estos medios del museo? ¿Qué expectativas generan en el jugador? En este artículo, haremos un repaso de los ejemplos más notables (como las sagas Broken Sword, Tomb Raider, Pokémon o Animal Crossing) y propondremos una categorización según sus características para estudiar posibles tendencias y entender qué percepción sobre estas instituciones podría te-

\begin{abstract}
Whether mysterious places or preservers of heritage, museums have become the perfect stage for videogames. Consequently, many users of all ages take a step into these places more often than they do in real life, opening their doors to new audiences. What is the image of the museums reflected in these games? What expectations do they create? In this paper, we will look at some remarkable examples (such as the Broken Sword, Tomb Raider, Pokémon or Animal Crossing sagas) and propose a new classification according to their characteristics in order to study possible trends and understand the public's perception of these institutions based on their image in this mass industry.
\end{abstract}

Cómo citar este trabajo / How to cite this paper:

Molina Martín, Rafael. "¡Roba, colecciona, mira y disfruta! Museos en videojuegos.” Atrio. Revista de Historia del Arte, no. 25 (2019): $258-277$.

(C) 2019 Rafael Molina Martín. Este es un artículo de acceso abierto distribuido bajo los términos de la licencia Creative Commons Attribution-

NonCommercial-ShareAlike 4.0. International License (CC BY-NC-SA 4.0). 
ner el público, a raíz de la imagen que se da en esta industria de masas.

Palabras clave: museo; videojuego; expolio; humanidades digitales; Tomb Raider; Animal Crossing.
Keywords: museum; videogame; looting; digital humanities; Tomb Raider; Animal Crossing.

En los últimos años, se ha escrito bastante sobre las ventajas y desventajas que la aplicación de las nuevas tecnologías puede tener en los museos, y sobre cómo intervienen en la correcta percepción de las colecciones por parte del público. Una de estas tecnologías, la del videojuego, se encuentra cada día más lejos de ser percibida como liviano entretenimiento infantil, llegando a una época de madurez con consumidores de todos los perfiles, a los que se llega gracias tanto a las grandes superproducciones como a los juegos realizados por pequeños estudios. No en vano, el videojuego ha llegado a ser la industria de ocio más potente en la actualidad, haciendo temblar al cine con sus altísimos presupuestos y sus aún mayores recaudaciones y repercusión social. ${ }^{1}$

Entre quienes vivimos por y para la cultura, el museo es una opción habitual para nuestros momentos de ocio. Fuera este círculo, hay un gran porcentaje de personas que han visitado estos espacios en muy pocas ocasiones, numerables con los dedos de las manos, resultando una experiencia que no recuerdan como satisfactoria. ${ }^{2}$ Pensamos que la única forma de conocer el museo es visitándolo y, sin embargo, muchas personas han tomado contacto más veces por medio de películas y videojuegos que personalmente (como referente del mainstream acercándose a los museos, tenemos el reciente videoclip de Apeshit, ${ }^{3}$ donde Beyoncé y Jay-Z posan autocráticamente ante La Gioconda).

Dentro de estos medios, nos parecía especialmente interesante el videojuego porque ofrece una mayor interactividad. Normalmente, nos permiten navegar libremente por grandes escenarios, e incluso microcosmos, mundos enteros que poseen una historia propia que nos animan a descubrir. Como parte de ellos, el museo hace acto de presencia tanto de forma anecdótica como con asombroso cuidado y gran protagonismo argumental. Y así es cómo una gran parte del público visita antes un museo virtual que uno real. ${ }^{4}$ ¿Qué es lo que ven? Después de jugar a un videojuego, ¿el museo les parecerá un lugar apasionante o un espacio aburrido? ¿Les generará una imagen irreal de museo como espacio de aventuras? ¿Serán conscientes del importante rol que estos lugares ocupan en nuestra sociedad? A estas preguntas intentaremos responder con varias conjeturas, fruto de la exposición de varios casos muy representativos de juegos con bastante éxito comercial. Pero antes, creemos necesario hacer varias aclaraciones.

\footnotetext{
1. Con unos beneficios que crecen sin parar año tras año, a nivel global destaca el completo análisis de la industria que hace anualmente la compañía Newzoo. Tom Wijman, Orla Meehan y Bente de Heij, "Global games market report," Newzoo, 2019, consultado el 12 de junio de 2019 ,

https://newzoo.com/solutions/standard/market-forecasts/global-games-market-report/ o las estadísticas facilitadas por "Si hay una industria que no es un juego, esa es la del videojuego," En digital, 6 de junio de 2018, consultado el 12 de mayo de 2019, https://en.digital/blog/videojuegos-industria-mobile-crecimiento En España, la industria sigue esta tendencia en alza, hasta ahora solo por detrás de la industria del libro, como se señala en El País: Ángel Luis Sucasas, "El crecimiento de la industria del videojuego amenaza el liderazgo del libro," El País, 31 de enero de 2019, consultado el 12 de junio de 2019 , https://elpais.com/cultura/2019/01/30/actualidad/1548877027_372955.html

2. Al respecto, e incluso habiendo mediación, son reveladores los datos de Joan Santacana Mestre et al., "¿Museos inclusivos o 'exclusivos'? La percepción de los adolescentes sobre el patrimonio, los museos y su didáctica," en Identidad, ciudad y patrimonio. Educación histórica para el siglo XXI, eds. Sebastián Molina Puche, Nayra Llonch Molina, y Tània Martínez Gil (Gijón: Ediciones Trea, 2016), 153-65. Precisamente este estudio demuestra con cuestionarios el mayor interés que sienten los adolescentes por medios como las videoconsolas frente al museo.

3. Disponible en plataformas digitales como Youtube: Beyoncé y Jay Z, "Apeshit", consultado el 12 de junio de 2019, https://www.youtube.com/watch?v=kbMqWXnpXcA

4. Fue de sumo interés al decidirme a escribir este artículo encontrar a alguien que, con otros ejemplos y un enfoque distinto, parecía compartir esta inquietud colgando sus impresiones en playthepast.org, un interesante blog sobre videojuegos y patrimonio: Thomas Brown, "The role of museums in videogames," Playthepast, 6 de junio de 2014, consultado el 13 de mayo de 2019, https://www.playthepast.org/?p=4717
} 
En primer lugar, no vamos a hablar de traslaciones de museos reales al mundo virtual, ${ }^{5}$ sino de espacios nuevos creados especialmente para el videojuego. Además, independientemente de la verosimilitud con la que sean representados, no nos centraremos en aquellos casos cuyo objetivo principal sea la divulgación -incluidas las exposiciones exclusivamente virtuales-. Al contrario, queremos ver aquellos casos comerciales, no educativos, que invitan al usuario a jugar y utilizan el museo como pretexto.

Por otro lado, consideramos necesario hacer un apunte sobre aquellos juegos que cuentan con un público eminentemente infantil de aquellos con carácter más adulto. En el primer grupo, quizás esta sea una de las primeras tomas de contacto del jugador con el espacio del museo, gracias a la cual se generarán unas determinadas expectativas. En el segundo, puede ser un buen momento para que vuelvan a conectar con un espacio que no suelen incluir en su oferta de ocio. Sobre ellos, y demostrando lo asentado que está el videojuego como entretenimiento para todos los públicos, nos dice la Asociación Española de Videojuegos ${ }^{6}$ que al menos un 38,9\% de los españoles adultos juegan a videojuegos, de los que un $26,2 \%$ declaran hacerlo de forma habitual. De estos porcentajes, es algo superior la cifra de hombres que la de mujeres, tratándose mayormente de personas menores de 45 años — la implicación es drásticamente menor por parte del público que supera esta edad-.

Habiendo aclarado esto, pasamos a estudiar esta representación de una forma más concreta por medio de tres categorías que nos ayudarán a comprender los usos que se han dado a este espacio como escenario: El museo como lugar de aventuras, como centro de prestigio y como preservador de la memoria de un colectivo

\section{El museo como lugar de aventuras}

La primera categoría que hemos querido analizar es la del museo como lugar de aventuras, ya que es la más abundante y, probablemente, la más esperable de un medio de ocio. Aquí, nuestros edificios van a ser un lugar tentador donde infiltrarnos, ya sea para convertirnos en verdaderos expoliadores o para resolver enigmáticos misterios.

Uno de los géneros donde antes y de una forma más común empezaron a florecer este tipo de escenarios es la aventura gráfica, ${ }^{7}$ probablemente influida por el espíritu de Indiana Jones. ${ }^{8}$ Esta franquicia cuenta con dos juegos de este género desarrollados entre finales de los 80 y la primera mitad de los 90 por una Lucasart Adventure Games que vivía una época dorada. No vamos a centrarnos en estos juegos, pero queríamos mencionarlos ya que la mayoría de los casos desarrollados en esta categoría9 beben del mito de arqueólogo/ historiador intrépido y heroico reflejado en la estrella de Hollywood. ${ }^{10}$

\footnotetext{
5e este tipo de representaciones se habla en otras publicaciones como Chairi Kiourt, Anestis Koutsoudis y Dimitris Kaelles, "Realistic Simulation of Cultural Heritage," International Journal of Computational Methods in Heritage Science issue 1, no. 1 (2017): 10-40.

6. En su estudio realizado en 2015 a mil personas mediante encuestas telefónicas: AEVI y SIGMA DOS, Videojuegos y adultos (Madrid: AEVI, 2015).

7. Género que vivió su momento de oro en los 90, como acertadamente señalan Simone Belli y Cristian López Raventós, "Breve historia de los videojuegos," Athenea Digital, no. 14 (2008): 159-79

8. Los efectos de la mitificación del arqueólogo, gracias a figuras como Indiana Jones, se han estudiado en textos como Louise Zarmati, "Popular archaeology and the archaeologist as hero," en Gendered archaeology: the second Australian Women in Archaeology Conference, eds. Jane Balme y Wendy Beck (Canberra: ANH Publications, 1995), 43-47. Aquí ya se ve que el arqueólogo-héroe, además de eminentemente masculino, suele causar destrucción y caos allá donde pasa.

9. Respecto al papel de la figura del arqueólogo en videojuegos y cómo es percibida por el público, es de gran interés Andrew Reinhard, "Playing as Archaeologists," cap. 2 en Archaeogaming: An Introduction to Archaeology in and of Video Games (New York: Berghahn Books, 2018), 62-87.

10. Sobre los precedentes y el establecimiento del mito del arqueólogo como héroe, citamos a Kevin McGeough, "Heroes, Mummies and Treasure: Near Eastern
} 
Buen ejemplo de ello es la primera entrega de las cinco con la que cuenta la saga Broken Sword, es decir Broken Sword. La leyenda de los templarios, ${ }^{11}$ lanzado originalmente en 1996 para ordenadores. En ella encarnamos a un abogado americano, George Stobbart que, acompańado de una periodista, Nicole Collard, se dispone a destapar toda una serie de conspiraciones templarias tras ser testigo fortuito del atentado en una cafetería durante su estancia en París. Con este pretexto, recorreremos ruinas, palacios y lugares misteriosos de países como Irlanda, Siria, Espańa o Francia.

En los primeros compases del juego, tras encontrar un manuscrito medieval en París, nos acercaremos a un museo ficticio, el Musée Crune (Fig. 2), para hablar del artefacto encontrado con el profesor especializado en estudios medievales André Lobineau. Ya desde ahora podemos señalar algo crónico en la representación del museo en el videojuego, y que iremos viendo con otros ejemplos: la conquista absoluta de Francia y su capital, París, sobre la imagen que las desarrolladoras y el público tienen de la cultura. Si hay un museo o un gran misterio que resolver, es bastante seguro que este transcurra o muestre claras inspiraciones en el Louvre u otros espacios que remitan a este territorio.

El Musée Crune se nos presenta como una cámara de las maravillas, ${ }^{12}$ donde la iluminación es tenue y la disposición de los objetos no tiene un orden lógico aparente, con multitud de piezas de culturas muy distintas conviviendo en este arbitrio — ya sea arte prehistórico, renacimiento europeo, el antiguo Egipto o la América precolonial—.

Analizándolo con detenimiento, desde el nombre hasta el carácter del espacio, apreciamos cierta inspiración en el Museo Cluny de París, algo que se confirma al ver colgada en una de sus paredes, recibiendo el impacto directo de la luz solar a través de una ventana, una de las piezas más emblemáticas de esta colección: uno de los tapices, La vista, del ciclo La Dame à la licorne, realizado a finales del siglo XV. Sin embargo, no parece que la relación vaya más allá de la referencia en el nombre, la ubicación en el mapa de este París virtual y una obra clave, ya que mientras que el museo real se centra especialmente en el arte medieval y algo de arte antiguo, en el de Broken Sword aparecen obras como El beso de Camille Claudel y sarcófagos egipcios. Por supuesto, este escenario no comparte apenas ninguna similitud con los museos actuales, las obras se superponen unas sobre otras y apenas hay presencia de cartelas o elementos que ayuden al usuario a disfrutar de la visita. Cuando interactuemos con las obras, veremos cómo Stobbart hace burla de alguna de ellas, especialmente las prehistóricas, al ser "rocas", mientras que admite disfrutar de otras, como el citado tapiz, sobre el que declara poder estar mirándolo todo el día.

Tendremos que visitar el museo por segunda vez para conocer al peculiar Lobineau, que nos contará algunos aspectos "históricos" que componen un tópico argumento sobre inquisición, monarcas y templarios que sirve de telón de fondo a nuestra historia. En nuestra tercera visita, donde descubriremos más aspectos de la trama, nos esconderemos dentro de uno de los sarcófagos egipcios del museo para pasar la noche y evitar

Archaeology in the movies," Near Eastern Archaeology, no. 69, 3-4 (2006): 174-85. Huelga decir que estas mismas características también se aplican a protagonistas de videojuegos como Lara Croft —citada por el autor dada su adaptación cinematográfica—o Nathan Drake.

11. Volviendo a remitir a la influencia de Indiana Jones, el propio Charles Cecil, responsable de Broken Sword, admitió en una entrevista sentirse muy influenciado por Indiana Jones, en busca del arca perdida. Peter Rootham-Smith, "Charles Cecil (interview)," Gameboomers, 2014, consultado el 29 de junio de 2019, http://www.gameboomers.com/interviews/CharlesCecil/CharlesCecil.htm

12. Tipología descrita en multitud de publicaciones como Maria Teresa Fiorio, "Dallo studiolo alle grandi collezioni principesche," cap. 1 en II museo nella storia. Dallo studiolo alla raccolta publica (Milano: Bruno Mondadori, 2011), 9-30. 


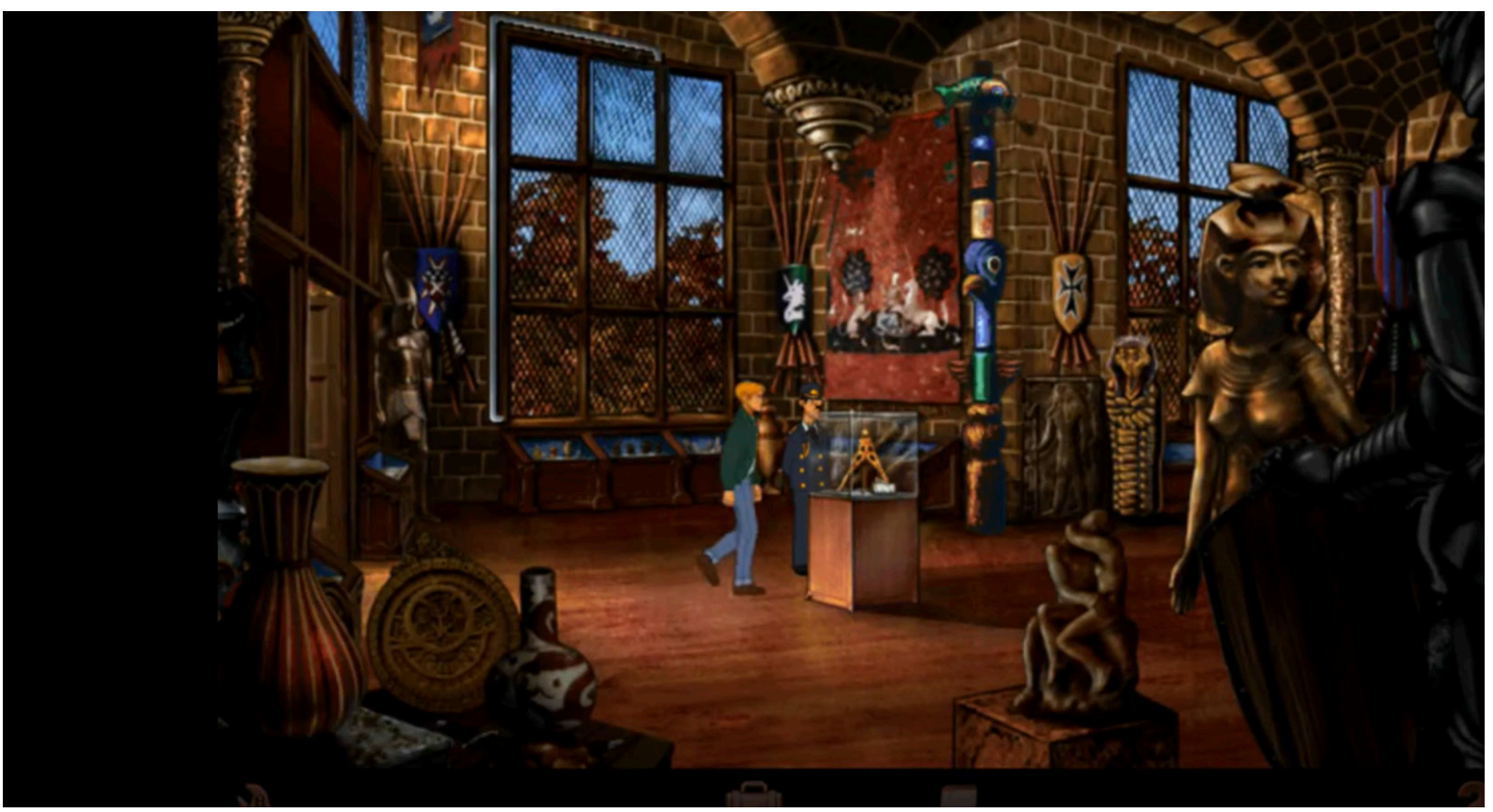

Fig. 2. Captura de pantalla del interior del Museo Crune (Broken Sword: la leyenda de los templarios. Captura del autor. Derechos de Revolution Software Ltd.).

el robo de un misterioso trípode que nuestros enemigos persiguen. Cuando los ladrones lleguen, el protagonista empujará hacia ellos otra de las piezas del museo, un tótem de varios metros de altura, para evitar que culminen su plan. Finalmente, es gracias a la intervención de Nicole Collard cuando logramos nuestro propósito. En realidad, no es que hayamos evitado un robo, sino que a la mańana siguiente despertaremos con el trípode en casa: esta herramienta será vital para para desentrañar todos los misterios del juego. En pocos minutos, y con asombrosa facilidad, nos hemos infiltrado en un museo, causado daño a las obras e incluso robado una pieza que pretendíamos proteger.

De similar modo ocurre en Secret Files: Tunguska, aventura gráfica originalmente lanzada en 2007 para ordenadores por la desarrolladora alemana Fusionsphere. En ella, encarnamos a Nina Kalenkov en la desesperada búsqueda de su padre, desaparecido por un misterio relacionado con el bólido de Tunguska. El primer escenario serán las salas y despachos del Naturkunde Musem de Berlín —que apenas comparten similitudes con las reales_-, del que nuestro progenitor es director científico.

Tras pasearnos de noche por sus salas y despachos con asombrosa facilidad, constataremos la desaparición de nuestro padre y notaremos que alguien ha estado registrando estas estancias poco antes. Así, el museo será un gran puzle donde tendremos que potenciar nuestro ingenio en búsqueda de respuestas. La mayor peculiaridad es el hecho de que estamos ante un museo de ciencias naturales en el que, sin embargo, tienen gran protagonismo los bienes arqueológicos de civilizaciones antiguas. Esto lo vemos en el despacho de uno de los trabajadores del museo - y nuestro mayor colaborador en la aventura-, dado que por reformas en la sala 8 las obras allí ubicadas han sido movidas a este lugar, donde se amontonan sin que, aparentemente, se haya tomado alguna medida de seguridad o haya preocupación por su integridad. De hecho, para resolver 
un puzle será preciso que Nina fracture una de las extremidades de un tótem sin mostrar demasiado remordimiento por ello.

Aun así, en este caso las consecuencias de nuestra visita serán más inocuas: para nuestra pesquisa será necesario reordenar una colección de monedas, descubrir un secreto oculto en un disco azteca o encontrar una puerta secreta en la peana del esqueleto de un dinosaurio. En ningún caso se llegará a los extremos de alguno de los ejemplos de esta categoría, donde saquear o destrozar museos y colecciones supondrá una constante.

Antes de pasar al extremo contrario, cabe citar un último caso, el del arqueólogo Hershel Layton, protagonista de la saga de Level-5 El profesor Layton, ${ }^{13}$ que desde 2007 ha sumado 6 entregas divididas en dos trilogías, sin contar Layton Brothers: Mistery Room para teléfonos móviles o la nueva dirección de la saga con El misterioso viaje de Layton: Katrielle y la conspiración de los millonarios, protagonizada por la detective privada Katrielle Layton, hija del profesor. En sus juegos, se nos propone agudizar nuestros instintos explorando entornos, conversando y resolviendo puzles para desentrańar misterios de todo tipo. En El profesor Layton y la Máscara de los Prodigios viajaremos a la ciudad de Montedore para investigar la identidad de un misterioso caballero enmascarado hacedor de peligrosos prodigios con los que atrae la atención de las autoridades, los ciudadanos y los turistas. Uno de estos "milagros" será el de dar vida a los retratados en varias réplicas de cuadros donados anónimamente al Museo Montsarton, uno de los puntos más monumentales de la ciudad. En él conoceremos a Artie, conservador del espacio, que nos contará algunos detalles sobre la misteriosa donación con la que el enmascarado pudo engañar a todos los presentes. Así, en nuestra visita al museo, Layton y sus ayudantes quedarán admirados por las obras que pueblan las dos galerías que podemos visitar, una de ellas con preeminencia de esculturas marmóreas, recordando a espacios como el Braccio nuevo de los Museos Vaticanos, y otra con preeminencia de pintura y producción contemporánea. El museo es, en este juego, un punto de interés capital de la ciudad, razón por la que el enmascarado decidirá utilizarlo para llamar la atención.

De las pausadas aventuras gráficas pasamos a los juegos de aventuras en tres dimensiones que, respondiendo al frenetismo clásico de este género, convierten al museo en un escenario ideal para expolios, tiroteos e infiltraciones, dando una imagen algo distorsionada de lo que estas instituciones deberían significar.

Como icono de una industria, no podríamos empezar por otro caso que no fuese el de la arqueóloga inglesa Lara Croft, ${ }^{14}$ ya que mantiene un estrecho vínculo con los museos. ${ }^{15}$ Como es habitual, en sus aventuras visitaremos museos ficticios, como el museo de antigüedades de Nueva York por el que pasamos en Tomb Raider: Curse of the Sword (2001). Sin embargo, en ocasiones los desarrolladores se inspiran directamente en museos reales, siendo un caso emblemático Tomb Raider: El Ángel de la Oscuridad (2003), donde visitamos el Museo del Louvre. El argumento de esta entrega está plagado de tópicos, con la intervención de antiguas organizaciones secretas como "La Cábala" o "Lux Veritatis" y alquimistas del siglo XV creando potentes armas de

13. De nuevo, otra saga que demuestra que los videojuegos son mucho más que un inofensivo juguete. Respecto a las aventuras de Layton, se ha escrito mucho sobre cómo ayuda a desarrollar la lógica de los jugadores mediante la gamificación. Véase Ruth Sofhía Contreras Espinosa, "Acercamiento a las características de los videojuegos y sus beneficios en el aprendizaje," en Actas del II Congreso Internacional de Videojuegos y Educación (Cáceres, 1-3 de octubre de 2013)، coords. Francisco Ignacio Revuelta Domínguez et al. (Madrid: Bubok Publishing, 2014), 381-94.

14. En el caso de Lara Croft, a la clásica imagen del héroe-arqueólogo, se suma un extenso debate sobre la construcción masculina de una heroína hipersexualizada, algo que se intentó corregir con el reinicio de la saga que hizo Crystal Dynamics en 2013. Queda claramente sintetizado en Esther Maccallum-Stewart, "'Take That, Bitches!' Refiguring Lara Croft in Feminist Game Narratives," Game Studies issue 2, no. 14 (2014), http://gamestudies.org/1402/articles/maccallumstewart Recordemos que también se habla de Croft en McGeough, "Heroes, Mummies and Treasure: Near Eastern Archaeology in the movies," $174-85$.

15. De hecho, Croft aparece como trabajadora del Museo Británico de Londres en los cómics Tomb Raider y Lara Croft y el presagio congelado, publicados por Dark Horse Comics en 2013 y 2015 respectivamente. 
destrucción. Así, teniendo como objetivo reunir las pinturas obscuras, que nos darán acceso al arma, descubriremos que una de ellas se encuentra escondida en el Museo del Louvre (Fig. 1), y será nuestra misión infiltrarnos de noche en su interior para localizarla. Empezaremos en el impresionante y laberíntico sistema de alcantarillado del museo, desde donde accederemos con explosivos a su interior. Algo que nos adelanta este impresionante sistema de evacuación es que el ocio y el factor espectacular se van a priorizar frente a la rigurosidad.

Consecuentemente, veremos colgadas en las paredes del Louvre obras ajenas a este museo, como $\mathrm{El} \mathrm{Na}$ cimiento de Venus de Botticelli. Además, colecciones de arqueología y bellas artes conviven en el espacio sin una lógica interna aparente, por lo que una sala cargada de relieves egipcios antecede, sin complejos, a la obra de la Gallerie degli Uffizi, que a su vez aparece rodeada de vasijas y ánforas en vitrinas. No obstante, hay algo de cierto en esta representación del museo, ya que sus autores han captado el carácter enciclopédico de sus colecciones, ${ }^{16}$ y lo han reflejado de una forma exótica, uniendo decenas de piezas radicalmente opuestas en el mismo espacio.

La seguridad del museo será nula, por lo que desactivar alarmas, esquivar medidas de seguridad y librarnos de los vigilantes será muy sencillo —al menos, han tenido el "detalle" de que hagamos esto último con descargas eléctricas-. Las salas, todas con un aspecto regio y llenas de galerías y arcos, estarán repletas de esculturas egipcias, griegas y romanas. Vitrinas, relieves colgados en las paredes y otros elementos no son más que grandes plataformas que desplazar y sobre las que saltar para evitar que salten las alarmas.

Por su lado, La Gioconda preside una sala en la que convive con algunas obras que le son vecinas en la vida real, como Las bodas de Caná de Veronese, pero también con otras que no tienen absolutamente nada que ver, como la Inmaculada Concepción de Tiepolo del Museo Nacional del Prado. Resulta llamativo, porque el equipo hizo viajes a París y Londres para mejorar la ambientación. ${ }^{17}$ Lo más apegado a la realidad es la barandilla y el cristal que protegen a la Mona Lisa, pero eso ni eso impedirá que podamos inmiscuirnos por un conducto de ventilación que hay sobre ella. Además, como detalle curioso, esta obra comparte pared con dos lienzos en miniatura de lo que en realidad son dos de los frescos más reconocidos del renacimiento italiano, La ultima cena de Leonardo da Vinci y La escuela de Atenas de Rafael Sanzio.

Sin entrar en demasiados detalles, tras ello nos colaremos en las salas de seguridad y despachos del museo, y descubrimos una enorme excavación arqueológica ${ }^{18}$ debajo del museo que conduce a una gigante sepultura subterránea en la que nos acecharán enormes peligros. ${ }^{19}$ Tras terminar nuestro recorrido, quien haya probado este juego pensará que un museo es un lugar de aventuras, conspiraciones y secretos, caracterizado por altos sistemas de seguridad — fácilmente franqueables si eres Lara Croft - y compuesto de galerías abovedadas de aspecto regio donde conviven obras maestras de todo tipo. Sin embargo, es La Gioconda el

16. María Dolores Jiménez Blanco, "Enciclopedia," cap. 4 en Una historia del museo en nueve conceptos (Madrid: Cátedra, 2018$), 73-98$.

17. Al menos, así lo reconoce en una entrevista Richard Morton, artista y escritor habitual de la saga, que en esta entrega ejerció de jefe de diseño: "we had quite a few 'research' trips to various locations including (...) Paris with the Louvre as its centrepiece. The team almost got kicked out of the Louvre because someone took pictures of the security systems". Entrevista realizada por Ash Kaprielov, "The interview with Richard Morton," Tomb of Ash, consultado el 12 de mayo de 2019, https://tomb-of-ash.tumblr.com/post/148144640105/the-interview-with-richard-morton

18. Sobre el tratamiento que la saga hace de las excavaciones arqueológicas en los videojuegos ver Meghan L. Dennis, "Archaeogaming, Ethics, and Participatory Standards," SAA Archaeological Record, no. 16-5 (2016): 29-33.

19. Un interesante campo cada día más en boga es el Archaeogaming, el estudio de la proyección que la arqueología y sus profesionales han recibido en numerosos juegos. En relación a nuestra investigación, es común la reflexión sobre la abundante destrucción y poca preocupación por el patrimonio que en los videojuegos se da. Al respecto destacamos la gran cantidad de información y amplia bibliografía disponible en www.archaeogaming.com y publicaciones como Dennis, "Archaeogaming, Ethics, and Participatory Standards," 29-33. Una completa definición la da el autor del blog Archaeogaming en Reinhard, "Introduction," Archaeogaming: An Introduction to Archaeology in and of Video Games (New York: Berghahn Books, 2018 ), 1-22. 
elemento icónico y veraz que hace que creamos que realmente estamos en el Museo del Louvre y no en cualquier otro espacio expositivo.

En la actualidad, es Nathan Drake quien ha cogido el testigo de Lara Croft como máximo representante de los juegos de aventuras. Protagonista de la saga Uncharted, ${ }^{20}$ cuyas entregas principales han sido desarrolladas por la compañía americana Naughty Dog. Cazatesoros y apasionado de las civilizaciones antiguas, Nathan Drake se considera antecesor de sir Francis Drake. De nuevo, en esta saga el museo aparece en varias ocasiones como marco inigualable para nuestras aventuras: dentro de su patrimonio, siempre habrá un objeto clave para llegar a un gran tesoro oculto durante siglos. Así ocurre en Uncharted 2: El reino de los ladrones, donde visitaremos el Museo Palacio de Estambul en dos ocasiones: en el modo multijugador, para enfrentarnos a disparos contra jugadores de todo el mundo o, en el modo historia, para robar una lámpara de aceite que se encuentra en la exposición Viajes de Marco Polo y que será de vital importancia en nuestro viaje.

En Uncharted 3: La traición de Drake, volveremos a un museo para descubrir cómo nuestro protagonista consiguió uno de los elementos más icónicos de su atuendo, el anillo de Sir Francis Drake, que lleva colgado del cuello. Además de repetir como escenario del modo multijugador, en el modo historia viajaremos al Museo Marítimo de Cartagena (Fig. 3), Colombia, encarnando a un joven Nathan de 14 años, lugar donde nos cruzaremos por primera vez con nuestro mentor y compañero Victor Sullivan.

En cierto modo, la recreación de este videojuego es mucho más verosímil respecto al Louvre de Lara Croft, y no solo por el evidente salto gráfico. Huelga decir que el parecido con la realidad es mínimo, tanto en la representación exterior como interior del edificio, pero sí resulta una opción más creíble e incluso respetuosa con el concepto de museo. Como parte de una exposición temporal que ha atraído la curiosidad del protagonista, El Pirata Francis Drake, visitaremos las salas del museo y veremos que en él se exponen una gran cantidad de objetos testigos de la vida y época del protagonista de la muestra: cañones, armas, maquetas, joyas, vestimentas, esqueletos animales e incluso documentos. Además, la cartelería del espacio y la señalética que se usa a lo largo de la exposición es bastante similar a la que se suele atribuir al museo tradicional. De este modo, se presenta ante nosotros un museo como espacio de conocimiento y ocio, donde hay una exposición aparentemente coherente centrada en un tema concreto. Quizás el hecho de no haber intentado representar un lugar tan fácilmente reconocible como el Louvre ha jugado a su favor, pero en Uncharted el escenario no parece un parque temático, sino un trabajado recurso argumental. Durante la primera visita, nuestro personaje solo podrá andar tranquilamente por las salas del museo, y contemplar los objetos que más interés nos causen mientras buscamos el anillo. El joven aventurero intentará profanar la vitrina donde la joya se encuentra, pero observará que está cerrada con llave. En ese momento, veremos que alguien más en la sala, Sullivan, está interesado en el objeto y además posee una llave para conseguirlo; por ello, nos decidiremos a hurtar la llave y colarnos en el museo de noche. Dada la nula seguridad del museo, no tendremos apenas dificultades en lograr nuestro fin, viniendo los problemas cuando Sullivan y nuestra futura enemiga, Marlowe, intenten quitarnos el anillo, provocando una trepidante huida por los tejados de Cartagena.

Estos ejemplos muestran lo mucho que los videojuegos beben en sus argumentos y ambientaciones del cine. Como novedad, los casos que veamos a partir de este punto van a dar una visión cada vez más plural 


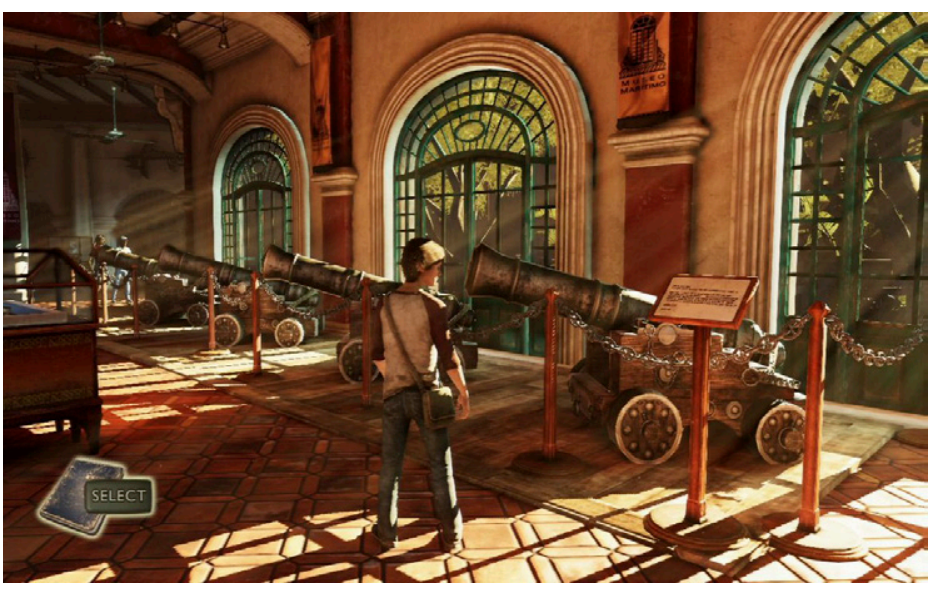

Fig. 3. Interior del Museo Marítimo de Cartagena (Captura de pantalla de Uncharted 3, subida por MAT a Mobygames. Derechos de Sony, disponible en

https://www.mobygames.com/game/ps3/uncharted-3-drakes- deception/screenshots/gameShotld,531804/ ). de estos edificios, creando posibilidades menos evidentes y mucho más gratificantes desde nuestro ámbito de estudio. Evidentemente, eso no resta valor a los casos citados hasta ahora; un videojuego es, ante todo, un producto de ocio que debe entretener. Desde ese prisma, mucho de los juegos aquí nombrados son exponentes de su género. Independientemente de eso, la visión que dan de los museos resulta algo desesperanzadora: no son interesantes por su contenido y su relación con la sociedad, sino por los misterios y secretos que esconden. Además, el objeto patrimonial solo es una herramienta más, por lo que su integridad física resulta secundaria.

\section{El museo como centro de prestigio}

En la categoría presente, veremos una propuesta de carácter más templado en la que, si bien se da una imagen menos tópica del museo, no se llega a profundizar demasiado en sus significados.

Los protagonistas van a ser los simuladores de construcción de ciudades, entre los que la veterana saga Simcity ${ }^{21}$ es considerada un estandarte gracias al excelente Simcity 4, lanzado para ordenadores en 2003. En el juego, se nos propone ser alcaldes de una ciudad que construiremos desde cero, gestionando sus recursos y distribuyendo las zonas residenciales, comerciales e industriales a nuestro antojo. La propuesta es sencilla, pero su profundidad y complejidad enorme, por lo que manejar ciudades de gran tamaño puede resultar un verdadero reto ¿Queremos que nuestros ciudadanos sean felices? ¿Que tengan una buena educación y sanidad? ¿O preferimos rápidos beneficios valiéndonos de grandes industrias? Sean cuales sean nuestras elecciones, debemos saber gestionar sus consecuencias, ya sean unos elevados impuestos o una gran contaminación.

Aquí, los museos tienen una gran utilidad, ya sirvan para educar a los ciudadanos o para atraer al turismo, pero el tratamiento que se les da suele ser bastante simple. En el caso de SimCity 4 tenemos dos tipos de museos, que en esencia son iguales, pero al ser uno de ellos de una categoría superior tiene más capacidad, costes de mantenimiento y efectividad. ¿Su utilidad? Educar a la población como si se tratase de una escuela. De hecho, ni siquiera actúa como un espacio de ocio, sino exclusivamente como un centro de educación que solo hace efecto a habitantes de más de treinta años — más efectivo conforme mayores sean los

21. Sus cualidades para el aprendizaje se nombran en numerosas publicaciones. Señalamos a Luis Albarracín, "Diseñando ciudades en SimCity," Suma+, no. 78 (2015): 65-71; Contreras Espinosa, "Acercamiento a las características de los videojuegos y sus beneficios en el aprendizaje," 381-94. Como caso práctico concreto de sus beneficios, remitimos a Natalia Monjelat y Laura Méndez, "Videojuegos y diversidad: construyendo una comunidad de práctica en el aula," Revista de Educación a Distancia, no. 33 (2012), https://revistas.um.es/red/issue/view/13931 
ciudadanos, teniendo su mayor ratio de éxito en adultos de más de 80 años-. ${ }^{22}$ No resulta un edificio demasiado versátil, sino un recurso para contentar a un sector de la población y, a lo sumo, un elemento decorativo más debido a su suntuosa apariencia; el museo no atraerá al turismo, y por alguna razón que no queremos aventurar, tampoco tendrá efecto alguno sobre la gente joven.

Como alternativa, en este mismo juego, podemos ubicar "monumentos" especiales que solo sirven para decorar y conseguir un incremento del valor comercial de la zona donde se ubiquen. Entre estas opciones hay ejemplos por todos conocidos como la Estatua de la Libertad, pero también museos. Es el caso del Museo Americano de Historia Natural, el Taipei Fine Arts Museum o el Museo Guggenheim de Nueva York (Fig. 4). Si analizamos otros juegos similares, quizás

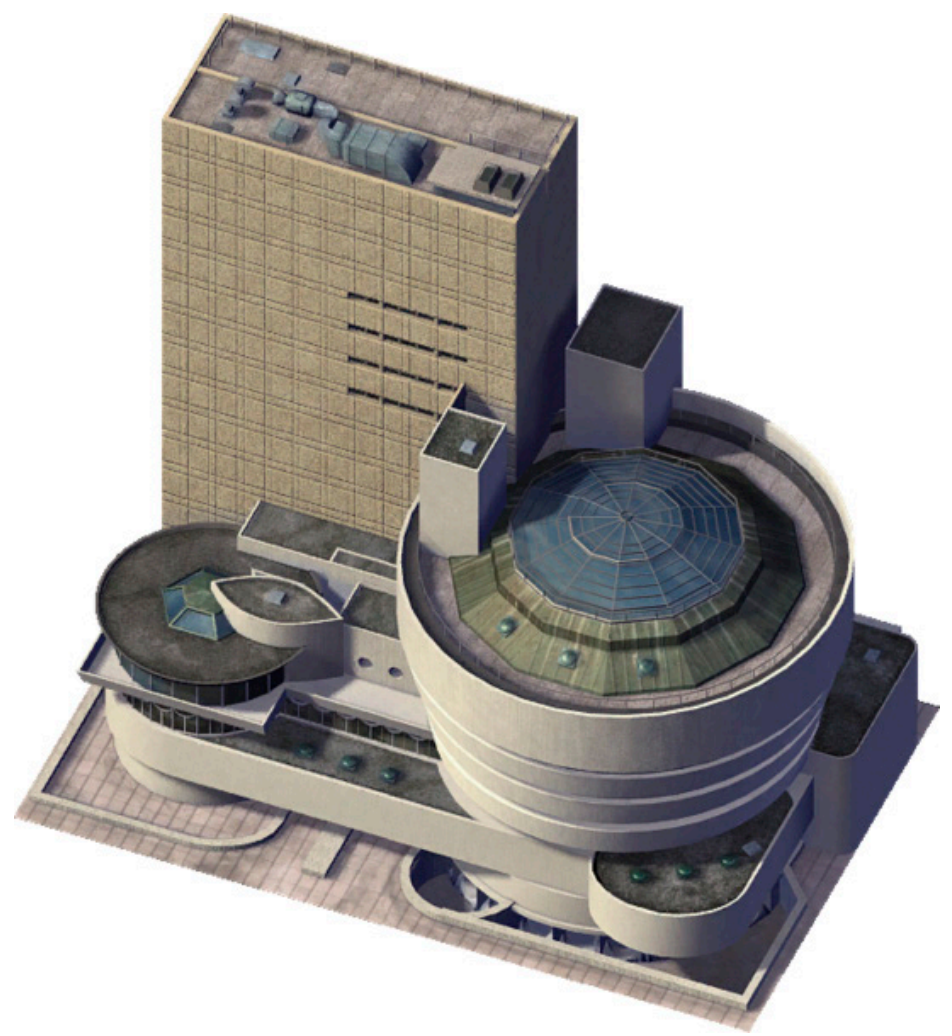

Fig. 4. Imagen del Museo Guggenheim de Nueva York en Simcity 4 (Subida por mervintalley49 a Freepng.es. Derechos de Maxis). el mayor referente actual en el género sea Cities Skylines, lanzado en 2015, donde de nuevo el museo tiene unas funciones muy limitadas. En este caso, simplemente sirven para atraer al turismo y generar riqueza — una imagen aún más distorsionada de lo que en realidad deberían ser sus funciones-.

\section{El museo como preservador de la memoria de un colectivo}

En este apartado nos gustaría relatar aquellos ejemplos en los que se da una visión más profunda y concreta de lo que es un museo. No, no es un mero escenario de aventuras, un lugar donde se exhiben lujosas piezas que debemos robar o que esconde secretos ocultos que descifrar. Así, las desarrolladoras nos presentan un lugar tranquilo y sosegado donde los personajes van a conocer la historia de su comunidad por medio de productos patrimoniales. Curiosamente y aunque esta pueda parecer una concepción más madura propia de juegos de contenido y aspecto adulto, en muchos casos este tipo de museo aparece representado en videojuegos en apariencia inofensivos, e incluso infantiles. Si los juzgásemos por su estética, hay quien podría pensar que tienen poco que ofrecer a nuestro tema.

22. Las estadísticas de los edificios se han obtenido de varias entradas de la wiki dedicada al juego: Sc4devotion, consultado el 13 de mayo de 2019 : https://www.wiki.sc4devotion.com/index.php?title=Main_Page 
Uno de estos casos es la saga superventas Animal Crossing, que desde 2001 ha aparecido en prácticamente todas las consolas de Nintendo, e incluso en teléfonos móviles. Su propuesta nos invita a ser aldeano en una apacible villa y disfrutar de la vida cotidiana y las relaciones personales con nuestros zoomorfos vecinos. Para entretenernos, se nos reta a recolectar todo tipo de objetos, peces e insectos que aparecen y desaparecen según el día, la hora y la estación. Con nuestra colección de objetos podremos hacer multitud de cosas; exhibirlos en casa, regalarlos a nuestros vecinos, venderlos o, en el caso que nos interesa, donarlos al museo.

En efecto, este edificio aparece en las entregas principales de la saga desde que esta aterrizó en la consola Gamecube en 2002. En él, dependiendo del juego, encontramos distintas dependencias. Las más importantes son las salas dedicadas a la exposición de fósiles, insectos, peces y obras de arte, aunque también hemos encontrado cafeterías donde se celebran conciertos, observatorios donde podemos contemplar las constelaciones o designar las nuestras propias e incluso una tienda donde comprar muebles y herramientas especiales. En Animal Crossing: New Leaf, también podremos alquilar varias estancias para decorarlas a nuestro gusto y abrirlas como exposiciones. Como podemos ver, prácticamente quedan representadas las principales estancias de cualquier museo, que no es solo un lugar estático y silencioso, sino también un espacio cambiante y de ocio donde podemos ir a charlar con nuestros vecinos, oír música en vivo o hacer compras.

En sí, esta representación ya es interesante y estamos seguro de que ha hecho llegar una imagen positiva a una gran cantidad de jugadores (hay que tener en cuenta que la entrega más vendida, New Leaf, lleva ya 12,21 millones de copias). ${ }^{23}$ Sin embargo, la propuesta va más allá, ya que cuando comencemos a jugar el museo estará completamente vacío y seremos nosotros los que llenaremos cada una de las salas con nuestras donaciones. Por esta tarea recibimos una doble recompensa: en primer lugar, los premios que nos van dando el conservador y su hija — Sócrates y Estela, dos búhos-, por otro, la satisfacción de ver cómo poco a poco, con nuestros hallazgos, se va reconstruyendo el esqueleto de los dinosaurios, o cómo el precioso acuario se va llenando de peces de colores. Con ello, no solo se saca a flote nuestra faceta coleccionista, sino también nuestro lado solidario, ya que invertimos tiempo y esfuerzos en enriquecer las salas del museo de esta pequeña comunidad, para que sus vecinos puedan disfrutar de su contenido. Podemos venderlas, o incluso exhibir a los objetos y criaturas en nuestra propia casa, pero el resultado es menos grato. El museo es un verdadero aliciente para que entendamos que el patrimonio es un bien común, y que su provecho es mucho mayor cuando todos podemos beneficiarnos de sus virtudes. Este edificio, de corte clásico, ya que normalmente presenta una fachada de piedra decorada con pilastras y un gran frontón, se convierte en el orgullo de nuestra partida, el lugar donde podemos mostrar de forma eficaz el resultado de nuestras horas de juego. ${ }^{24}$

Una curiosidad está en la forma de obtener las obras de arte (Fig. 5), para lo que vamos a tomar como ejemplo la entrega, New Leaf, al ser la última que ha visto la luz en la saga principal. En total, encontraremos 33 piezas que podremos donar al museo ( 25 pinturas y 8 esculturas) todas basadas en ejemplos reales, y tomando referencias tan distintas como la loba capitolina, el busto de Nefertiti, La joven de la perla, Las meninas, Un bar de las Folies Bergère e incluso la Gran Ola de Kanagawa, quedando representada una interesante variedad de

\footnotetext{
23. Tal y como reveló la propia Nintendo al compartir sus datos fiscales en marzo de 2019. Nintendo, "Datos financieros a julio de 2019 ," consultado el 10 de julio de 2019, https://www.nintendo.co.jp/ir/en/finance/software/3ds.html

24. Como contrapunto, se ha señalado que el juego induce al usuario a tendencias consumistas neoliberales, algo alrededor de lo que terminan girando muchas de sus facetas aparentemente positivas - como el reciclaje- Robert Poole y Sydney Spangler, "Eco this and recycle that': an ecolinguistic analysis of a popular digital simulation game," Critical Discourse Studies, 2019, consultado el 10 de junio de 2019, https://www.tandfonline.com/doi/full/10.1080/17405904.2019.1617177
} 
periodos y nacionalidades (arte antiguo de Egipto, Grecia y Roma e incluso un dogu prehistórico japonés, pinturas de artistas ingleses, neerlandeses, españoles, italianos y franceses). ${ }^{25}$ Para adquirirlas, debemos contactar con Ladino, un astuto zorro que establecerá una carpa en el pueblo un día aleatorio de cada semana, de 10:00 a 12:00 de la mañana. ${ }^{26}$ La elección de este animal no es para nada casual; parece representar con cierta sorna la imagen que se suele tener del sistema del arte, y es que entre las obras a la venta hay caras falsificaciones, razón por la que debemos agudizar nuestros sentidos. ¿Y qué hacemos para no ser

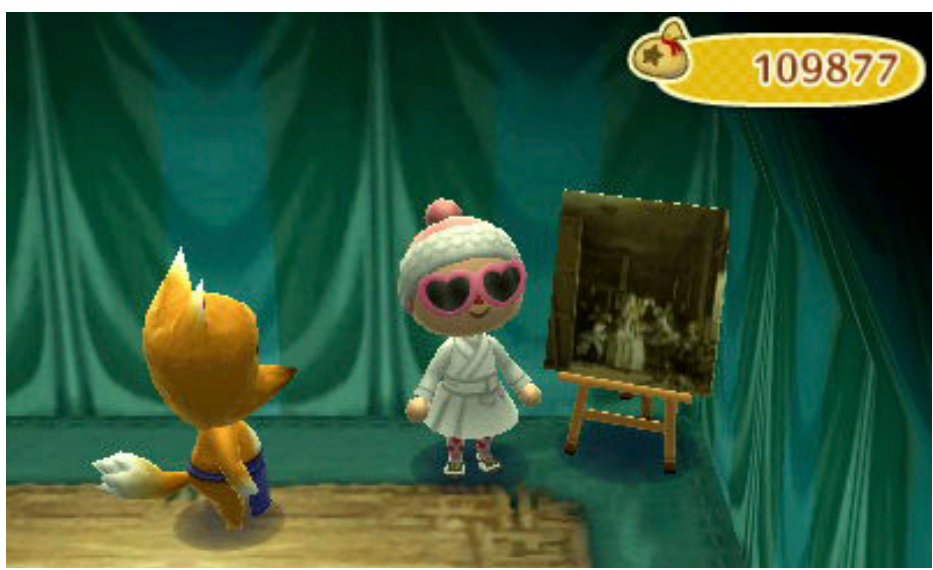

Fig. 5. Protagonista de Animal Crossing posando frente a una falsificación de Las meninas en la tienda de Ladino (Captura de pantalla de Animal Crossing. New Leaf subida por Jennifer Christensen en su web sosostris.com. Derechos de Nintendo, disponible en: http://www.sosostris.com/2013/03/31/animal-crossing-new-leaf-days-142-144/ ). estafados? Aquí entra un claro componente educativo, ya que para asegurarnos de comprar un original debemos conocer la obra real, buscar una imagen y compararla con las presentes en la carpa en búsqueda de diferencias. Por ejemplo, en la falsificación de Las Meninas el tamaño de la infanta Margarita multiplica a la del Museo del Prado. Con esta tarea se induce al jugador a familiarizarse con las obras de artes reales si quiere ahorrarse esfuerzos innecesarios en el juego. ${ }^{27}$

Pokémon, una de las sagas más exitosas del mundo de la cultura de masas, con un enfoque absolutamente transmedia, ${ }^{28}$ tiene una gran legión de seguidores de todo carácter y edades, aunque muestra una gran preocupación por captar al público escolar. Donde muchos padres ven un entretenimiento más para sus hijos, se esconden unos títulos que intentan educar al jugador de forma sutil e introduciendo una gran cantidad de contenido — no solo mecánicas de juego— de forma asequible. Cabe citar el mimo que Pokémon muestra intentando reflejar diferentes culturas, regiones y costumbres en sus cartuchos ${ }^{29}$ —especialmente en lo relativo a Japón, aunque con sus cuatro últimas entregas se han abierto a Estados Unidos (Teselia), Francia (Kalos), Hawái (Alola) e Inglaterra (Galar)—. Dentro de los pequeños continentes plagados de pueblos y ciudades que cada nueva entrega principal de Pokémon trae como novedad, encontramos la intención de construir un trasfondo cultural coherente con toda una mitología basada en la relación de los humanos con las criaturas protagonistas, sitios naturales e históricos, gastronomía típica y, en la mayoría de los casos, museos. Sí, aunque sea en lo último que pensamos al imaginar a los Pocket Monsters, el museo se ha convertido en un espacio recurrente en sus entregas, habiéndolos de todo tipo y repartidos por las distintas regiones (de arte, ciencias naturales, de los océanos e incluso un museo minero introducido en Pokémon Diamante/Perla, 2006).

25. De nuevo, esta información ha sido facilitada por la propia Nintendo en la guía oficial del juego. Guías Nintendo, "Guía oficial de Animal Crossing. New Leaf," consultado el 10 de mayo de 2019, http://www.guiasnintendo.com/0a_NINTENDO_3DS/animal_crossing_new_leaf/animal_crossing_new_leaf_sp/obrasarte.html 26. Una de las características principales de la saga es la de usar el reloj de la consola para cambiar el aspecto del pueblo y mostrar eventos distintos en cada partida.

27. Como conclusión, y aunque también se habla del cariz capitalista de la saga, citamos a Jim Kim, "Interactivity, user-generated content and video game: an ethnographic study of Animal Crossing: Wild World," Continuum, no. 28:3 (2014): 357-70. En esta publicación se habla de las posibilidades del trabajo en equipo gracias al juego con otros usuarios vía online o local. Gracias a ellos, podemos recibir consejos, intercambiar objetos y completar nuestra colección.

28. Sobre el impacto de la saga en sus inicios, ver Steven L. Kent, "And the Cycle Continues," cap. 29 en The ultimate history of video games: from Pong to Pokémon - the story behind the craze that touched our lives and changed the world (New York: Three Rivers Press, 2001$), 557-72$.

29. De ello hablan autores como Carlos Naranjo Bejarano, "El patrimonio japonés en 'Pokémon'," en Japón y "Occidente": El patrimonio cultural como punto de encuentro, ed. Anjhara Gómez Aragón (Sevilla: Aconcagua Libros, 2016), 773-82. 
Estos edificios, convertidos en un punto clave de aquellas ciudades en las que se enmarcan, son un punto ideal para que los jugadores se familiaricen con la historia de cada región y se paren a reflexionar sobre el folclore propio de Pokémon. En la mayoría de entregas, este edificio sirve para que los científicos devuelvan a la vida los fósiles de aquellas criaturas casi extintas que encontremos a lo largo de nuestra aventura. Sin embargo, en ocasiones esto va más allá. En el Museo de Ciudad Calagua (Pokemón Rubi, Zafiro y Esmeralda), mientras que la primera planta está llena de obras de arte, la segunda está vacía, y será el conservador el que nos invite a buscar obras vibrantes y contemporáneas para colgar de sus paredes —algo que haremos ganando combates y obteniendo con ello retratos de las criaturas-.

Quizás el momento más brillante desde este punto de vista llegó con la región de Kalos (Pokémon $X / Y)$, lanzados internacionalmente en 2013. Esta fue la segunda ocasión en la que Gamefreak, su desarrolladora, se alejó de la cultura japonesa, inspirándose en Francia para crear una región donde el patrimonio tiene una importancia vital, por lo que está colmada de castillos, palacios y otros monumentos como menhires, especialmente concentrados en su capital, Luminalia, convertida en potencia turística dentro del cosmos del juego. Así, aparte de sus restaurantes, cafeterías y amplias y regulares avenidas que conforman un trazado urbanístico circular y regular (similar al de ciudades como Palmanova), destacan dos hitos arquitectónicos, la Torre Prisma y un museo, inspirados claramente en la Torre Eiffel y el Museo del Louvre respectivamente. Sí, por si cabía alguna duda, ciudad Luminalia es el equivalente al París que todos conocemos.

En lo relativo al museo (Fig. 6), de gran extensión y con tres plantas de altura, en la entrada el personal nos ofrece adquirir la audioguía para complementar nuestra visita; tal y como sucedería en un museo tradicional. Las obras, en las dos primeras plantas, no son más que ilustraciones de ciudades, criaturas y mecánicas jugables de la saga, y el contenido de la audioguía sirve para que los jugadores vayan conociendo, casi sin proponérselo, el trasfondo de Pokémon. Además, en ellas se reproducen los recursos más habituales en la interpretación del patrimonio: de un retrato nos dicen que el autor ubicó a una criatura determinada, mew, para destacar la grandeza del retratado; en otro el pintor quería expresar su voluntad de estar conectado con los Pokémon; o, por ejemplo, una de las piezas resulta ser una obra maestra del movimiento realista.

La última planta muestra obras de un perfil más "clásico", alejadas de la apariencia de ilustración e imitando el aspecto de un cuadro ajado por el paso del tiempo. En este momento, sobre una de las obras, la audioguía indica que es el diseño original de un molino existente en otra de las ciudades, llevado a cabo por un artista con profundos conocimientos en pintura, arquitectura e ingeniería civil, lo que parece un guiño a Leonardo da Vinci.

Así, aunque el contenido sea relativo al universo Pokémon, muchas personas, especialmente niños, estarán haciendo una visita de no menos de 10 minutos a un museo, y además lo hacen de la forma más prototípica posible: van a recepción, compran la audioguía y proceden a deambular por las salas. Además, durante su recorrido se toparán con numerosos personajes no jugables que nos contarán lo satisfactorio que es el arte y lo que están disfrutando de la visita. Entre ellos, por ejemplo, está la conservadora del centro, que nos explica que su función es conseguir nuevas obras y planear exposiciones. Por tanto, mientras los usuarios juegan, están teniendo algunas nociones muy básicas de cómo funciona un museo, y además, se están generando en ellos unas expectativas coherentes a lo que significa un edificio de estas características. 


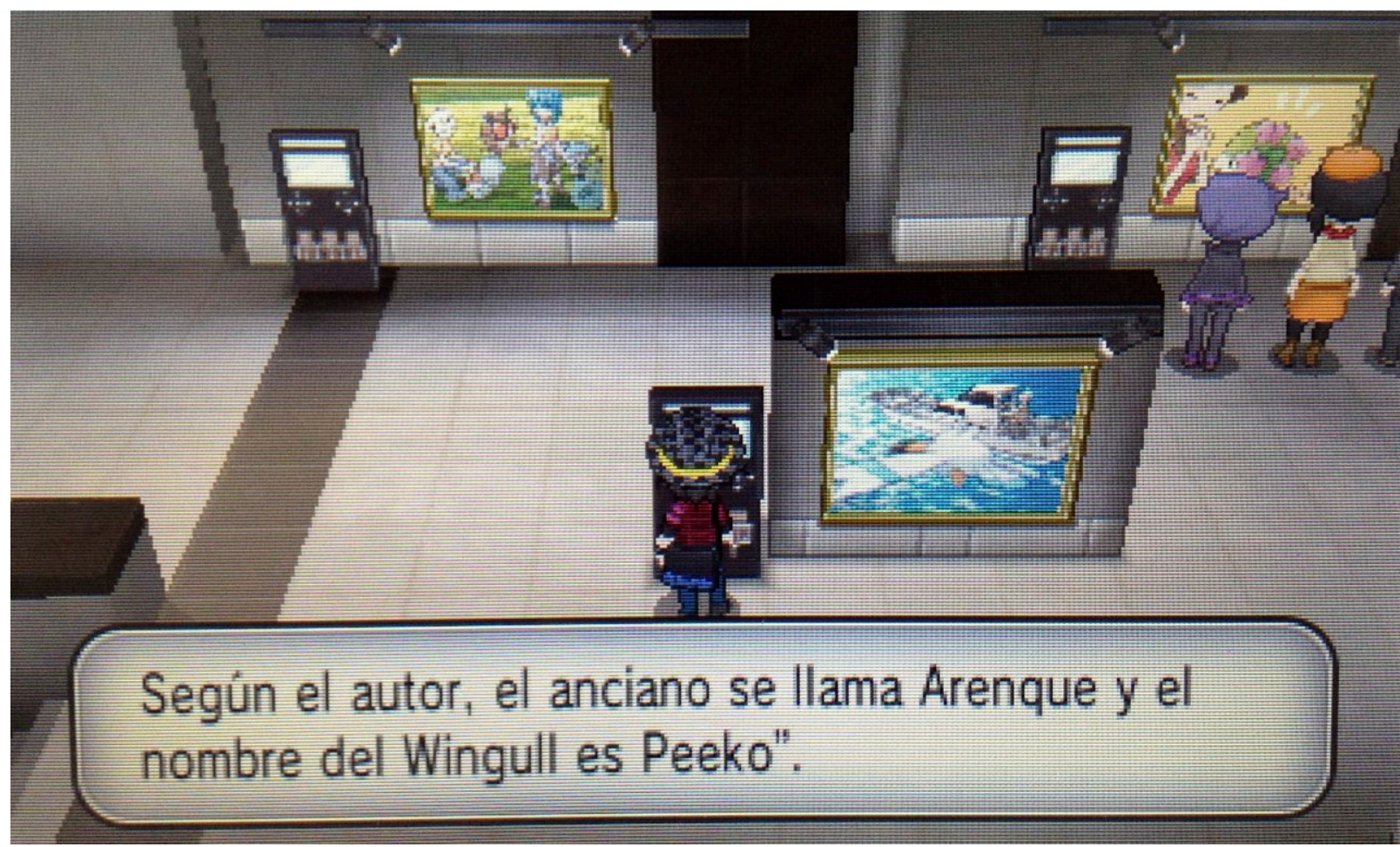

Fig. 6. Interior del museo de ciudad Luminalia (Captura de pantalla de Pokémon X/Y subida por el usuario Sekiam a pokemaster.es. Derechos de Nintendo, creatures inc. y Game freak Inc., disponible en https://pokemaster.es/referencias-en-pokemon-xy-a-pasadas-generaciones-op-1664/ ).

Es probable que muchos niños hayan recibido con mayor agrado la propuesta de ir a un museo después de haber visitado uno en sus juegos favoritos, sin tener ninguna noción previa de lo que estos lugares son. De forma somera, ya saben qué van a encontrar en un museo, cómo puede ser la visita y, además, tienen pequeñas nociones de quién puede trabajar ahí. No había necesidad de incluir este espacio y, sin embargo, haciéndolo se enriquece el universo del juego, y se ayuda a todos aquellos que trabajamos con el patrimonio, familiarizando a grandes masas de público con nuestro entorno de trabajo y mostrando un lugar donde pasarlo bien y relajarse. ${ }^{30}$

El último caso sobre el que nos vamos a centrar es la saga Yo-kai Watch, gran aprendiz de Pokémon en muchos aspectos, que ha gozado de bastante éxito entre el público infantil desde que Level 5 lanzara la primera entrega en 2012. Su pretexto es buscar a los Yo-kai, — unos extraños espíritus basados en la mitología japonesa - que con su presencia incontrolada están afectando a la vida diaria de nuestra ciudad, Floridablanca, y sus habitantes.

Para esta ocasión nos centraremos en la entrega Yo-kai Watch 2: Carnánimas/Fantaesqueletos, donde visitaremos una Floridablanca de dimensiones considerables, con un diseño encantador y gran cantidad de

30. Desgraciadamente, la cantidad de publicaciones científicas sobre estos juegos es aún muy reducida. Sin embargo, en nuestro trabajo ha sido de gran ayuda la labor que hacen las comunidades fans a la hora de recopilar información. En la siguiente página, se encuentran numerosos planos de los escenarios de la saga Pokémon, así como ilustraciones, comentarios y, en el caso del museo, las transcripciones de los textos de la audioguía, algo que ha facilitado mucho nuestro trabajo: Bulbapedia, "Lumiose Museum," consultado el 9 de mayo de 2019, https://bulbapedia.bulbagarden.net 
detalles. En uno de sus distritos, Colinas Aura, podremos visitar el Museo del Estanque Calabaza, que recibe tal nombre a causa del parque donde se encuentra. Una ciudad tan completa como Floridablanca no podía estar desprovista de un museo, espacio que se concibe como verdadero salvaguarda de la memoria de una comunidad a través de su colección.

Este edificio, en palabras de una de sus recepcionistas, tiene "exposiciones desde los dinosaurios hasta las bellas artes", es decir, vuelve a tener una concepción enciclopédica. El museo cuenta con dos plantas y cuatro salas expositivas, dos en cada una, además de dos espacios mixtos que sirven para comunicar las distintas plantas y los accesos a las salas. También encontramos una "cámara acorazada" donde se han situado varios peines de cuadros, además de dos estanterías con cajas que parecen guardar material arqueológico. Por toda la estancia hay apiladas cajas de madera donde reposan otras obras de arte sin orden o estabilidad aparente.

Como parte más tradicional, encontramos las salas de paleontología de dinosaurios y de arte contemporáneo, en el ala izquierda de la planta baja y la primera planta respectivamente. Todo es bastante usual en ellas, en la primera, se muestran restos fósiles en vitrinas, acompañados del gran cráneo de un triceratops y el esqueleto completo de un tyrannosaurus rex que, al principio, parecerá estar vivo al haber sido hechizado por uno de los fantasmas que pueblan la ciudad. Al hablar con uno de los visitantes veremos cómo descubre desilusionado, junto a su hijo, que no se trata más que de una réplica del original.

La sala alta, dedicada al arte contemporáneo, muestra la visión más extendida de este arte, con obras polémicas que los visitantes dicen no entender — es el caso de una especie de escultura gigante en forma de excremento morado que cuelga del techo, y que llama la atención de una niña- También hay particulares instalaciones, como proyecciones lumínicas de espirales giratorias en el suelo, o un ojo gigante cuyo iris es una gran espiral que gira sin cesar. Los colores de la sala son más estridentes, con paredes y suelo en tonos morados, rosáceos y naranjas, y vemos un camino serpenteante e irregular que la cruza de puerta a puerta y parece indicarnos un trazado sinuoso. En otro de los puntos, aparece una impactante obra, un brazo gigante que sale de la pared, apoyando la punta de sus dedos en el suelo y generando un túnel por debajo del que pasa el camino antes citado. Frente a una estrella giratoria gigante, un visitante sentencia: "La gente llama a este tipo de cosas 'vanguardia'. Yo digo que son sinsentidos”. Así, el arte contemporáneo es el que goza de un montaje más rompedor, pero también el menos entendido por los espectadores.

Las salas centrales, que distribuyen los espacios, muestran otras imágenes que parecen tener menos conexión con el resto del museo. Así, encontramos una especie de Victoria de Samotracia a la que le falta un ala, o cuadros de una clara vocación impresionista, con uno que guarda semejanzas con los cipreses de Van Gogh.

La parte más interesante se encuentra en el ala izquierda de ambas plantas, donde se ubica una exitosa exposición "especial” —así la llaman en el juego, entendemos que sería una exposición temporal—, Floridablanca: 60 años atrás. Esta exposición estará conectada con una mecánica del juego, los viajes en el tiempo, gracias a los que visitaremos la ciudad 60 años antes del presente. Así, como misión opcional, si hablamos con el conservador del museo podremos ayudarle a recuperar 10 objetos del pasado que resultan verdaderamente variopintos, como carteles publicitarios, peluches o, citando textualmente, "el famoso vestido de Mary Ronmo", en clara referencia a Marilyn Monroe. 
Así, el interior de la exposición se concibe en ambas plantas como una suerte de period rooms, donde se recrea el ambiente de la ciudad gracias a la pintura de las paredes, suelos, decoración y a los propios objetos expuestos; encontramos espacios que aluden al interior doméstico, a zonas comerciales e incluso al mundo del cine y la televisión.

La gran enseńanza que transmite este museo es que cualquier objeto es digno de ser musealizado porque nos habla de nuestra historia, tradiciones y sociedad. De todo podemos aprender, y a veces el patrimonio guarda significados ocultos que pueden pasar desapercibidos a priori. Tanto es así, que cuando donemos al museo un peluche que encontraremos en nuestra aventura, el conservador nos dirá que en realidad ese objeto se puso muy de moda ańos atrás, ya que se colocaba como adorno en la cabeza, a modo de sombrero. Las salas de la exposición estarán pobladas por piezas de todo género: juguetes, utensilios domésticos, películas —hay un proyector cuya cinta deberemos encontrar para que los usuarios puedan disfrutar de la proyección-. Incluso el videojuego aprovecha para reivindicar su industria, introduciendo una videoconsola antigua ante la incredulidad de un usuario, que declara: "Si esto está en un museo, quizás yo también debería estar en uno" ${ }^{31}$

Así, de forma sutil y completamente colateral, el juego está dando varias nociones de lo que es un museo a los jugadores. El museo es un espacio expositivo, donde se pueden mostrar objetos de todo tipo, desde obras de arte a piezas más cotidianas. Además, mientras que la zona arqueológica presenta una museografía tradicional, el arte contemporáneo se exhibe en una sala más divertida e imprevisible, y para hablar de la historia local se recrean ambientes concretos; en cierto modo, se reflejan las tipologías clásicas de museo y las peculiaridades expositivas de cada una, y se está manifestando que los museos no son necesariamente espacios monótonos. Asimismo se recalca, especialmente con el arte contemporáneo, lo difícil que resulta comprender el patrimonio, hasta el punto de que un asistente nos sugiere que: "Todo el mundo que va al museo parece inteligente. Si no entiendes algo, tu inclina la cabeza y di: 'Aaah, claro'”. Pero, entre todo el público, también hay quienes se sorprenden, disfrutan y aprenden. De hecho, de entre todas las líneas de dialogo escritas, la más prometedora es pronunciada por una joven estudiante que deambula sin parar de sala a sala y dice: "Los museos son geniales. Mira todas estas cosas tan raras. Cuando sea mayor, quiero trabajar en un museo como este”. ¿Se habrá planteado por primera vez algún niño, gracias a un videojuego, que un museo puede ser un lugar divertido? O, mejor aún, ¿̨un trabajo al que dedicar su vida?

\section{Mejor existir que pasar desapercibidos}

Después de estas líneas, creemos haber demostrado que los museos son una constante más habitual de lo que podría parecer en el mundo del videojuego. Además, por muy diversas que sean las propuestas, se repiten unos tópicos comunes entre los que destacan la hegemonía cultural francesa y el halo de misterio que suele rodear a las piezas. La profesión de conservador aparece vinculada al museo en bastantes ocasiones, ya sea organizando

31. El debate de los videojuegos como obra de museo que parece plantearse con este detalle, no ha terminado de asentarse en el ámbito académico e incluso fuera de sus paredes, como se muestra en Emily Sharpe, "Videogames in museums: fine art or just fun?," The Art Newspaper. no. 265 (2015),

https://www.theartnewspaper.com/articles/Video-games-in-museums-fine-art-or-just-fun/36905 pero empieza a definirse con hechos como la organización de muestras como "The Art of Video Games", por el Smithsonian American Art Museum en 2012. Respecto a ello, ver Georgina Goodlander y Michael Mansfield, "Press Start: Video Games in an Art museum," Journal of interactive humanities, volumen 1, issue 1 (2013): 37-41. Actualmente, museos como el MoMA o el Victoria and Albert han empezado a añadir hardware y software relacionado con videojuegos en sus colecciones. Respecto a este último, destaca la celebración de septiembre de 2018 a febrero de 2019 de la exposición "Videogames: Design/Play/Disrupt". 
exposiciones o investigando un caso que pondrá su vida en peligro. Sea cómo fuere, lo importante es que los museos y sus trabajadores existen, y que los videojuegos contribuyen a que los jugadores dejen de percibirlos como un espacio extraño y ajeno a su vida. Independientemente de la razón por la que visitemos el museo en nuestra aventura, las impresiones suelen ser positivas; ya sea para robar una obra de arte o para hacer una donación, cuando el videojuego nos lleva al museo quiere que nos divirtamos $-\mathrm{y}$ lo cierto es que lo consigue—. ${ }^{32}$

Quizás lo más importante, a nuestro modo de ver, es que el mero hecho de que los museos resulten tan recurrentes significa que generan interés en las desarrolladoras y los jugadores. Nuestra postura, como profesionales, podría ser la de enfrentarnos a esta corriente y batallarla porque la representación de los museos no es como querríamos. Sin embargo, resulta mucho más enriquecedor abrazar esta inquietud y hacer algo constructivo con ella. Debemos rebatir los falsos mitos siendo conscientes de la diversión que un videojuego puede aportar, del vínculo emocional que puede haber con sus jugadores y de su valor intrínseco.

Por lo tanto, nuestra misión sería la de aprovechar ese caudal de emociones que el videojuego genera y usarlo para que los visitantes descubran el verdadero valor de las colecciones y las actividades que en estos espacios se realizan. ${ }^{33}$ Un factor importante en este proceso será que en las plantillas de los museos haya involucradas personas que también disfruten del videojuego y piensen en estrategias para incluirlos en sus programas. Esto, en realidad, es algo que ya ha comenzado, como vemos en espacios como el Victoria and Albert Museum de Londres, donde trabajadores como Kieran Long han manifestado abiertamente su pasión y la han introducido en su puesto laboral (en su caso, contribuyendo a que el museo adquiera videojuegos y organice actividades relacionadas con este medio)..$^{34}$

Por último, parece absolutamente necesario que los profesionales de la cultura entren a formar parte del mundo del videojuego, y sean capaces de asesorar a los equipos para que las representaciones tornen con más frecuencia a una dirección constructiva. No hay que olvidar la capacidad educativa que tienen los videojuegos, incluso cuando son concebidos con una función puramente lúdica: no solo mejoran nuestros reflejos, sino que una simple ambientación o la aparición de un personaje histórico puede conseguir, a un nivel superficial, que los usuarios se familiaricen con aspectos que salen de su vida cotidiana. ${ }^{35}$ Cada día aparecen en el mercado juegos con una documentación histórica más rigurosa - a la mente de todos viene la saga Assasins Creed, que destaca por recrear ciudades como París en la revolución francesa o Florencia y Roma en el renacimiento-,${ }^{36}$ o incluso son los propios museos los que se animan a crear videojuegos para tener voz propia en esta gran industria —en este aspecto, destacan las dos entregas de Nubla que propulsó

\footnotetext{
32. Recordemos que no siempre ocurre así en los museos, citando a Santacana Mestre et al., "¿Museos inclusivos o «exclusivos»? La percepción de los adolescentes sobre el patrimonio, los museos y su didáctica," 153-65.

33. En este caso, Fosaluzza habla de cómo los museos podrían trabajar no solo generando juegos propios, sino con juegos que ya están en el mercado. Ver Marianne Fosaluzza, "Museum games. What video games could bring to museum education," 2016, consultado el 29 de septiembre de 2019 ,

https://www.academia.edu/31109552/Museum_games_What_video_games_could_bring_to_museum_education

34. Emily Sharpe. "Videogames in museums: fine art or just fun?"

35. Cristian López Raventós, "El videojuego como herramienta educativa. Posibilidades y problemáticas acerca de los serius games," Apertura. Revista de Renovación Educativa, vol. 8, no. 1, (2016): 136-51.

36. No es difícil encontrar declaraciones de los creadores del juego aludiendo a su preocupación por una adecuada ambientación histórica, algo que ha terminado por convertirse en un recurso comercial. En una entrevista realizada por Laura Parker para Gamespot, Alexander Hutchinson, director creativo de Assassin's Creed III declaró: "We spent around six months reading books, Wikipedia entries, watching documentaries, and building out huge flow charts", para poco después hablar del nativo americano que les ayudó con testimonios de la América colonial. Véase Laura Parker y Alexander Hutchinson, "Recreating Colonial America in Asassin's Creed III," Gamespot, 2012, consultado el 02 de mayo de 2019, https://www.gamespot.com/articles/recreating-colonial-america-in-assassins-creediii/1100-6398835 Aun en estos ejemplos, la rigurosidad histórica debe postrarse ante las necesidades del guion, la raíz comercial y los complicados calendarios de desarrollo, como comentan Diego Téllez Alarcia y Diego Iturriaga Barco, "Videojuegos y aprendizaje de la historia. La saga Assasin's Creed," Contextos Educativos, no. 17 (2014): 145-55.
} 
el Museo Thyssen-Bornemisza de Madrid-. Estos indicios son esperanzadores, trabajando codo con codo, lograremos que la representación de los museos en el videojuego sea más realista, dejando atrás falsos mitos y logrando mostrar su verdadero atractivo a una gran cantidad de público.

AEVI y SIGMA DOS, Videojuegos y adultos. Madrid: AEVI, 2015.

\section{Referencias}

Albarracín, Luis. "Diseñando ciudades en SimCity.” Suma+, no. 78 (2015): 65-71.

Belli, Simone, y Cristian López Raventós. "Breve historia de los videojuegos." Athenea Digital, no. 14 (2008): 159-79.

Brown, Thomas. "The role of museums in videogames." Playthepast, 2014. Consultado el 13 de mayo de 2019. https://www.playthepast.org/?p=4717

Bulbapedia. "Lumiose Museum." Consultado el 9 de mayo de 2019. https://bulbapedia.bulbagarden.net

Contreras Espinosa, Ruth Sofhía. "Acercamiento a las características de los videojuegos y sus beneficios en el aprendizaje." En Actas del II Congreso Internacional de Videojuegos y Educación (Cáceres, 1-3 de octubre de 2013), coordinado por Francisco Ignacio Revuelta Domínguez, M. ${ }^{a}$ Rosa Fernández Sánchez, M. ${ }^{a}$ Inmaculada Pedrera Rodríguez, y Jesús Valverde Berrocoso, 381-94. Madrid: Bubok Publishing, 2014.

Dennis, Meghan L. "Archaeogaming, Ethics, and Participatory Standards." SAA Archaeological Record, no. 16-5 (2016): 29-33.

Fiorio, Maria Teresa. "Dallo studiolo alle grandi collezioni principesche." Cap. 1 en Il museo nella storia. Dallo studiolo alla raccolta publica, 9-30. Milano: Bruno Mondadori, 2011.

Fosaluzza, Marianne. "Museum games. What video games could bring to museum education." 2016. Consultado el 29 de septiembre de 2019. https://www.academia.edu/31109552/Museum_games_What_video_games_could_bring_to_museum_education

Goodlander, Georgina, y Michael Mansfield. "Press Start: Video Games in an Art museum.” Journal of interactive humanities volumen 1, issue 1 (2013): 37-41.

Guías Nintendo. "Guía oficial de Animal Crossing. New Leaf." Consultado el 10 de mayo de 2019. http://www.guiasnintendo.com/0a_NINTENDO_3DS/animal_crossing_new_leaf/animal_crossing_new_leaf_sp/obrasarte.html

Jiménez Blanco, María Dolores. "Enciclopedia." Cap. 4 en Una historia del museo en nueve conceptos, 73-98. Madrid: Cátedra, 2018.

Kaprielov, Ash. "The interview with Richard Morton.” Tomb of Ash. Consultado el 12 de mayo de 2019. https://tomb-of-ash.tumblr.com/post/148144640105/the-interview-with-richard-morton

Kent, Steven L. The ultimate history of video games: from Pong to Pokémon - the story behind the craze that touched our lives and changed the world. New York: Three Rivers Press, 2001.

Kim, Jim. "Interactivity, user-generated content and video game: an ethnographic study of Animal Crossing: Wild World.” Continuum, no. 28:3 (2014): 357-70.

Kiourt, Chairi, Anestis Koutsoudis, y Dimitris Kaelles. "Realistic Simulation of Cultural Heritage." International Journal of Computational Methods in Heritage Science issue 1, no. 1 (2017): 10-40.

López Raventós, Cristian. "El videojuego como herramienta educativa. Posibilidades y problemáticas acerca de los serius games." Apertura. Revista de Renovación Educativa, vol. 8, no. 1 (2016): 136-51.

Maccallum-Stewart, Esther. "'Take That, Bitches!' Refiguring Lara Croft in Feminist Game Narratives." Game Studies issue 2, no. 14 (2014). http://gamestudies.org/1402/articles/maccallumstewart 
McGeough, Kevin. "Heroes, Mummies and Treasure: Near Eastern Archaeology in the movies." Near Eastern Archaeology, no. 69, 3-4, (2006): 174-85.

Monjelat, Natalia, y Laura Méndez. "Videojuegos y diversidad: construyendo una comunidad de práctica en el aula." Revista de Educación a Distancia, no. 33 (2012). https://revistas.um.es/red/issue/view/13931

Naranjo Bejarano, Carlos. "El patrimonio japonés en 'Pokémon'." En Japón y “Occidente”: El patrimonio cultural como punto de encuentro, editado por Anjhara Gómez Aragón, 773-782. Sevilla: Aconcagua Libros, 2016.

Nintendo. "Datos financieros a julio de 2019." Consultado el 10 de julio de 2019. https://www.nintendo.co.jp/ir/en/finance/software/3ds.html

Parker, Laura, y Alexander Hutchinson. "Recreating Colonial America in Asassin's Creed III." Gamespot. Consultado el 02 de mayo de 2019 (2012): https://www.gamespot.com/articles/recreating-colonial-america-in-assassins-creed-iii/1100-6398835

Poole, Robert, y Sydney Spangler. "Eco this and recycle that: an ecolinguistic analysis of a popular digital simulation game." Critical Discourse Studies, 2019. Consultado el 10 de junio de 2019. https://www.tandfonline.com/doi/full/10.1080/17405904.2019.1617177

Reinhard, Andrew. Archaeogaming: An Introduction to Archaeology in and of Video Games. Nueva York: Berghahn Books, 2018.

Rootham-Smith, Peter. “Charles Cecil (interview).” Gameboomers, 2014. Consultado el 29 de junio de 2019. http://www.gameboomers.com/interviews/CharlesCecil/CharlesCecil.htm

Santacana Mestre, Joan, Tània Martínez Gil, Victoria López Benito y Nayra Llonch Molina. “¿Museos inclusivos o 'exclusivos'? La percepción de los adolescentes sobre el patrimonio, los museos y su didáctica." En Identidad, ciudad y patrimonio. Educación histórica para el siglo XXI, editado por Sebastián Molina Puche, Nayra Llonch Molina, y Tània Martínez Gil, 153-65. Gijón: Ediciones Trea, 2016.

Sc4devotion. Consultado el 13 de mayo de 2019. https://www.wiki.sc4devotion.com/index.php?title=Main_Page

Sharpe, Emily. "Videogames in museums: fine art or just fun?.” The Art Newspaper, no. 265 (2015). https:// www.theartnewspaper.com/articles/Video-games-in-museums-fine-art-or-just-fun/36905

"Si hay una industria que no es un juego, esa es la del videojuego." En Digital, 2018. Consultado el 12 de septiembre de 2019. https://en.digital/blog/videojuegos-industria-mobile-crecimiento

Sucasas, Ángel Luis. "El crecimiento de la industria del videojuego amenaza el liderazgo del libro." El Pais, 31 de enero de 2019. Consultado el 12 de junio de 2019, https://elpais.com/cultura/2019/01/30/actualidad/1548877027_372955.html

Téllez Alarcia, Diego, y Diego Iturriaga Barco. "Videojuegos y aprendizaje de la historia. La saga Assasin's Creed." Contextos Educativos, no. 17 (2014): 145-55.

Wijman, Tom, Orla Meehan, y Bente de Heij. “Global games market report.” Newzoo, 2019. Consultado el 12 de septiembre de 2019, https://newzoo.com/solutions/standard/market-forecasts/global-games-market-report/

Zarmati, Louise. "Popular archaeology and the archaeologist as hero." En Gendered archaeology: the second Australian Women in Archaeology Conference, editado por Jane Balme y Wendy Beck, 43-47. Canberra: ANH Publications, 1995. 